\title{
Syntheses of Isochromenes and Naphthalenes by Electrophilic Cyclization of Acetylenic Arenecarboxaldehydes
}

\author{
Dawei Yue, Nicola Della Cá, and Richard C. Larock \\ Department of Chemistry, lowa State University, Ames, IA 50011, USA, larock@iastate.edu
}

\begin{abstract}
Highly substituted $1 H$-isochromenes, isobenzofurans and pyranopyridines can be prepared by allowing $o$-(1-alkynyl)arenecarboxaldehydes and ketones to react with $\mathrm{I}_{2}, \mathrm{ICl}, \mathrm{NIS}, \mathrm{Br}_{2}, \mathrm{NBS}, p$ $\mathrm{O}_{2} \mathrm{NC}_{6} \mathrm{H}_{4} \mathrm{SCl}$ or $\mathrm{PhSeBr}$, and various alcohols or carbon-based nucleophiles at room temperature. Naphthyl ketones and iodides are also readily prepared by the reaction of 2-(1-alkynyl) arenecarboxaldehydes with $\mathrm{I}_{2}$ and simple olefins or alkynes.
\end{abstract}

\section{Introduction}

The electrophilic cyclization of functionally-substituted alkenes has provided an extremely useful route to a wide variety of heterocyclic and carbocyclic compounds, which have proven useful as intermediates in the synthesis of natural products and pharmaceuticals. ${ }^{1}$ Analogous chemistry of alkynes has been far less studied, although it would appear to be a very promising route to an extraordinary range of useful, functionally-substituted heterocycles and carbocycles. ${ }^{2}$ Our recent work and that of others have indicated that benzofurans, ${ }^{3}$ benzothiophenes, ${ }^{4}$ isoquinolines, ${ }^{5}$ indoles, $,{ }^{3 c}, 6$ isocoumarins, ${ }^{7}$ isoindolinones, ${ }^{8}$ polycyclic aromatics 9 and a number of other heterocycles 10 can be easily synthesized by the electrophilic cyclization of appropriate functionally-substituted alkynes using iodine-, bromine-, sulfur- and selenium-containing electrophiles under exceptionally mild reaction conditions (Scheme 1).

Not long ago, Yamamoto reported an interesting cyclization of acetylenic aldehydes to 1alkoxy- $1 H$-isochromenes catalyzed by $\mathrm{Pd}(\mathrm{OAc})_{2}$ (eq 1). ${ }^{11} \mathrm{The} \mathrm{Pd}(\mathrm{II})$ salt employed was

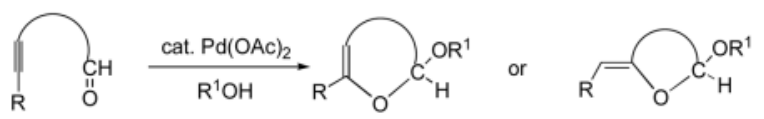

claimed to exhibit a dual role as both a Lewis acid and a transition-metal catalyst. Recently, a similar preparation of 4-iodo- $1 \mathrm{H}$-isochromenes has been achieved upon reaction of bis (pyridine)iodonium tetrafluoroborate $\left(\mathrm{IPy}_{2} \mathrm{BF}_{4}\right)$ and $\mathrm{HBF}_{4}$ with the same acetylenic carbonyl precursors in the presence of various nucleophiles (eq 2). ${ }^{12}$ The use of expensive

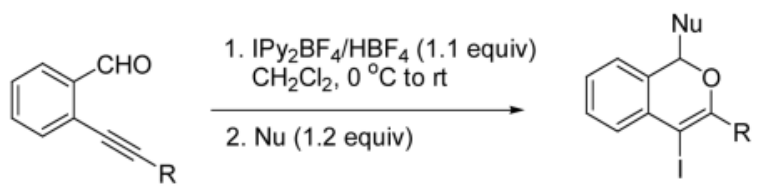


$\mathrm{IPy}_{2} \mathrm{BF}_{4}$ together with $\mathrm{B}(\mathrm{OMe})_{3}$ or toxic, strongly acidic $\mathrm{HBF}_{4}$, and the relatively complicated stepwise procedure employed have certain drawbacks synthetically. Furthermore, the full scope of this cyclization has yet to be reported.

We simultaneously found that this three component reaction ${ }^{13}$ proceeds smoothly by using the simple electrophiles ICl, NIS, $\mathrm{Br}_{2}, \mathrm{NBS}, p-\mathrm{O}_{2} \mathrm{NC}_{6} \mathrm{H}_{4} \mathrm{SCl}$ and $\mathrm{PhSeBr}$ to generate the corresponding iodine-, bromine-, sulfur- and selenium-substituted heterocycles in high yields under very mild reaction conditions. ${ }^{14}$ Herein, we wish to report further details on this efficient approach to heterocycles and carbocycles involving electrophilic cyclization using a range of electrophiles and nucleophiles.

\section{Results and Discussion}

Our initial studies were aimed at finding optimal reaction conditions for the electrophilic cyclization of the $o$-(1-alkynyl)benzaldehydes. Our investigation began with the reaction of $o$-(phenylethynyl)benzaldehyde (1), methanol and $\mathrm{I}_{2}$ (eq 3, Table 1). The reaction was first attempted using $0.25 \mathrm{mmol}$ of $o$-(phenylethynyl)benzaldehyde (1), 1.2 equiv of methanol, 1.0 equiv of $\mathrm{K}_{2} \mathrm{CO}_{3}$ and 1.2 equiv of $\mathrm{I}_{2}$ in $\mathrm{CH}_{2} \mathrm{Cl}_{2}$ at room temperature. Iodocyclization proceeded smoothly and provided an $88 \%$ yield of the desired product 2 . Other solvents, such as $\mathrm{CH}_{3} \mathrm{CN}$ and DMF, were also investigated and proved to be far less effective. $\mathrm{KHCO}_{3}$ and $\mathrm{NEt}_{3}$ were also investigated as bases. While $\mathrm{KHCO}_{3}$ provided a slightly lower yield of the desired product than $\mathrm{K}_{2} \mathrm{CO}_{3}, \mathrm{NEt}_{3}$ proved to be totally ineffective and none of the desired product was detected. Although $\mathrm{CH}_{2} \mathrm{Cl}_{2}$ is not a good solvent for $\mathrm{K}_{2} \mathrm{CO}_{3}$, the presence of $\mathrm{K}_{2} \mathrm{CO}_{3}$ was crucial for a clean, high yielding reaction. $\mathrm{K}_{2} \mathrm{CO}_{3}$ is presumed to neutralize the by-product $\mathrm{HI}$ of the electrophilic cyclization, which can also react with the acetylenic aldehyde and generate the corresponding pyrilium salt. ${ }^{15}$ Increasing the amount of methanol from 1.2 equiv to using $\mathrm{MeOH}$ as the solvent actually resulted in a lower yield. 1.2 Equiv of $\mathrm{I}_{2}$ has proven to be enough to achieve a high yield. Further increasing the amount of $\mathrm{I}_{2}$ did not give any better yield. Based on the above optimization efforts, the combination of 1.2 equiv of nucleophile, 1.0 equiv of $\mathrm{K}_{2} \mathrm{CO}_{3}$, and 1.2 equiv of $\mathrm{I}_{2}$ and using $\mathrm{CH}_{2} \mathrm{Cl}_{2}$ as the solvent at room temperature gave the best results. This procedure has been used as our standard reaction conditions for subsequent electrophilic cyclizations.

To explore the scope of this cyclization, other commercially available iodine, bromine, phosphorous, sulfur and selenium electrophiles have also been used in this process under similar reaction conditions. The results are summarized in Table 2 . It has been found that $\mathrm{I}_{2}$, NIS, ICl, NBS, $\mathrm{PhSeBr}$ and $p-\mathrm{O}_{2} \mathrm{NC}_{6} \mathrm{H}_{4} \mathrm{SCl}$ are all good electrophiles for the reaction of 2(phenylethynyl)benzaldehyde (1) and $\mathrm{MeOH}$, providing decent yields of the desired cyclization products (entries 1-7). The strong electrophile $\mathrm{Br}_{2}$ also readily reacted with aldehyde 1 to generate the desired cyclization product (entry 5). However, the reaction is not clean and only $21 \%$ of the desired product was obtained. Electrophiles, such as tert-

butylsulfinyl chloride and diphenylphosphinous chloride $\left(\mathrm{Ph}_{2} \mathrm{PCl}\right)$ did not react with aldehyde 1 and none of the desired product was observed (entries 8 and 9).

To further explore the scope of this chemistry, various nucleophiles have been tested in this process using 2-(phenylethynyl)benzaldehyde (1) and $\mathrm{I}_{2}$. Alcohols, such as $\mathrm{MeOH}, n-\mathrm{BuOH}$, $t$ - $\mathrm{BuOH}$ and 2-iodobenzyl alcohol, all react well and provide good to excellent yields of the desired iodocyclization products (entries 1 and 10-12). The reaction with $t$-BuOH provided only a modest yield due apparently to the steric hindrance of the tert-butyl group or perhaps dehydration of this alcohol (entry 11).

Nucleophiles other than alcohols have also been examined under our standard cyclization conditions. While the reaction using $N, N$-dimethylaniline as the nucleophile provided an 
excellent yield of the cyclization product (entry 13), those using phenol, thiophene, $\mathrm{N}$ methylindole, 5,5-dimethyl-1,3-cyclohexanedione and 1,3-cyclohexanedione only afforded modest yields of the desired cyclization products (entries 14-18). The reaction with phenol provided both carbon and oxygen trapping products (entry 14). The reactions which have produced carbon coupling products were highly regioselective. The 1,3-diketone reactions gave enol trapping products, plus some aldol product in the case of 5,5-dimethyl-1,3cyclohexanedione (entries 17 and 18). The reaction with the trimethylsilyl enol ether of acetophenone did not afford the desired cyclization product under our standard reaction conditions; only the aldol condensation product was observed. However, adding 1 equiv of KF as a promoter greatly affected the reaction pathway, affording a $63 \%$ yield of the desired cyclization product (entry 19). Other nucleophiles, such as benzofuran, benzylthiol, Meldrum's acid and 1-methoxy-2-methyl-1-(trimethylsilyloxy)propene failed to react under our standard reaction conditions and none of the desired products were observed (entries 20-23). Thiols did not prove to be useful nucleophiles, perhaps due to oxidation to disulfides by iodine. Primary and secondary amines have also been used as nucleophiles, but none of the expected products were formed.

To further examine the generality of this chemistry, acetylenic aldehydes bearing different substituents on the carbon-carbon triple bond were synthesized in high yields by palladium/ copper-catalyzed coupling of the appropriate $o$-bromoarenecarboxaldehydes and the corresponding terminal alkynes. ${ }^{16}$ The resulting acetylenic aldehydes were then allowed to react under our standard electrophilic cyclization conditions to afford the corresponding $1 \mathrm{H}$ isochromene products. Alkynes bearing an alkyl and a vinylic substituent on the triple bond also react well and provide the desired electrophilic cyclization products in good yields, when methanol and $N, N$-dimethylaniline are used as the nucleophiles (entries 24, 25, 27, 28 and 30). 4,5-Dimethoxy-2-(phenylethynyl)benzaldehyde (25) also underwent smooth iodocyclization, providing a quantitative yield of the $\mathrm{MeOH}$ trapped product (entry 31 ).

Besides the successful use of $\mathrm{PhSeBr}$ as an electrophile (entry 6, Table 2), we have also been able to extend this cyclization chemistry to sulfur electrophiles. Thus, aryl-, alkyl-, and vinylicsubstituted acetylenes undergo cyclization and provide sulfur-substituted isochromenes in 6074\% yields respectively (entries 7, 26 and 29). The reaction of aldehyde 25 and $p$ -

$\mathrm{O}_{2} \mathrm{NC}_{6} \mathrm{H}_{4} \mathrm{SCl}$ afforded only a $51 \%$ yield of the desired cyclization product, alongside a $45 \%$ yield of the product of simple addition of the electrophile to the carbon-carbon triple bond (entry 32 ).

Rather unstable 2-Ethynylbenzaldehyde (28) and 2-(trimethylsilylethynyl)benzaldehyde (29) have also been employed as aldehydes, but they did not undergo cyclization when $\mathrm{MeOH}$ and $I_{2}$ were used (entries 33 and 34). The reactions were messy and unidentifiable mixtures were observed instead.

Pyridinecarboxaldehyde derivatives $\mathbf{3 0}$ and $\mathbf{3 2}$ have also been allowed to react under our standard cyclization conditions using $\mathrm{MeOH}$ as a nucleophile and $\mathrm{I}_{2}$ or $\mathrm{ICl}$ as electrophiles. The electron-deficient aromatic ring of these aldehydes did not affect cyclization. We still obtained the desired iodocyclization products using aldehyde $\mathbf{3 0}$ and either $\mathrm{I}_{2}$ or $\mathrm{ICl}$ in $70 \%$ and 64\% yields respectively (entries 35 and 36). The presence of an electron-donating group on the aromatic ring on the distal end of the carbon-carbon triple bond greatly enhanced the cyclization and a $96 \%$ yield of the desired cyclization product was obtained when pyridinecarboxaldehyde $\mathbf{3 2}$ was employed (entry 37 ).

Besides aromatic carboxaldehydes, vinylic carboxaldehyde $\mathbf{3 4}$ has also been examined under our standard iodocyclization conditions. Using $\mathrm{I}_{2}$ and methanol, a 1:1 mixture of 5- and 6membered ring products was observed by ${ }^{1} \mathrm{H}$ NMR spectroscopic analysis (entry 38 ). Using 
NIS and $n$ - $\mathrm{BuOH}$, a mixture was again obtained, but this time the 5 -membered ring product was favored by a 7:1 ratio (entry 39). The ratio of 5- to 6-membered ring products thus varies depending on the nucleophile and electrophile used in the reaction.

We have also investigated the possibility of carrying out a double iodocyclization, which might be quite useful for the quick assembly of systems with extended conjugation. Compound $\mathbf{3 9}$ underwent smooth iodocyclization to afford the double cyclization product in a $75 \%$ yield (entry 40). In all cases where we have compared results, these reactions with readily available, inexpensive iodine have given higher yields than the corresponding process using the expensive iodonium salt and $\mathrm{HBF}_{4}$ reported by Barluenga. 12

We have also examined the cyclization of a ketone-containing alkyne. Ketone $\mathbf{4 1}$ has been allowed to react with $\mathrm{I}_{2}$ and methanol under our standard reaction conditions (entry 41). This reaction proceeded smoothly to provide a $90 \%$ yield of a 5-exo-dig cyclization product, rather than the 6-membered ring ether formed by the electrophilic cyclization of analogous benzaldehyde derivatives. The use of $\mathrm{K}_{2} \mathrm{CO}_{3}$ in our standard procedure provides very mild basic conditions and avoids the acid-initiated, partial decomposition of this cyclization product described by Barluenga. ${ }^{12}$

Interestingly, we were unable to get high yields of the desired iodocyclization products when we employed our reagents in a stepwise manner analogous to that described by Barluenga.

12 Instead, an unreactive solid, presumed to be the pyrilium salt, ${ }^{15}$ was generated. Based on this observation, a possible mechanism for our process is proposed in Scheme 2. We believe that these cyclizations proceed by anti attack of the electrophile and the carbonyl to produce a pyrilium intermediate. Before it forms an insoluble precipitate, ${ }^{15}$ the pyrilium intermediate is immediately trapped by the nucleophile present in the reaction mixture.

Recently, a number of new naphthalene synthesis have been reported, which involve alkyne cyclizations. ${ }^{17}$ For example, Barluenga et al have reported that $\mathrm{IPy}_{2} \mathrm{BF}_{4}, o$-alkynyl-substituted carbonyl compounds, and alkynes react to give 1-iodonaphthalene derivatives and the reaction with alkenes instead of acetylenes afforded related naphthyl ketone derivatives. ${ }^{17 \mathrm{~d}}$ Our studies have shown that the same substituted naphthalenes can be synthesized in high yields comparable to those obtained by Barluenga employing our $\mathrm{I}_{2}$ procedure and alkenes or alkynes as the trapping reagent (Scheme 3). The use of the more sophisticated iodonium reagent $\mathrm{IPy}_{2} \mathrm{BF}_{4}$ employed by Barluenga ${ }^{17 \mathrm{~d}}$ for this same process is not necessary. These reactions are believed to proceed through a similar pyrilium intermediate, which is trapped by the alkene or alkyne. Once again, the use of readily available, easily handled $\mathrm{I}_{2}$ greatly simplifies the procedure developed by Barluenga. ${ }^{17 \mathrm{~d}}$

We believe that this approach to heterocycles should prove quite useful in synthesis, particularly when one considers that there are many ways to transform the resulting halogen, sulfur and selenium functionalities into other substituents. For instance, the resulting heterocyclic iodides should be particularly useful intermediates in many palladium-catalyzed processes, such as Sonogashira, ${ }^{16}$ Suzuki, ${ }^{18}$ Stille, ${ }^{19}$ and $\mathrm{Heck}^{20}$ cross-couplings. For instance, compound 2 has been treated under standard Heck and Suzuki conditions, providing the corresponding coupling products $\mathbf{4 6}$ and $\mathbf{4 7}$ in $\mathbf{9 9 \%}$ and $\mathbf{7 9 \%}$ yields respectively (Scheme 4). Using the palladium-catalyzed annulation of an internal alkyne developed in our group, 21 we have been able to convert compound $\mathbf{2}$ to $\mathbf{4 8}$ in a $92 \%$ yield. Compound $\mathbf{2}$ is also readily oxidized to 4-iodoisocoumarin $\mathbf{4 9}$ in an $81 \%$ yield by using PCC (Scheme 4).

\section{Conclusions}

Efficient syntheses of a variety of substituted oxygen-containing heterocycles and carbocycles have been developed using the electrophilic cyclization of acetylene-containing aldehydes and 
ketones and the generality of this process has been explored. This method accommodates various functional groups and affords substituted heterocycles in good to excellent yields. The resulting iodoheterocycles are readily elaborated to more complex compounds by using known organopalladium chemistry. Although Barluenga $12,17 \mathrm{~d}$ reported similar reactions using $o$-(1alkynyl)benzaldehydes and $\mathrm{IPy}_{2} \mathrm{BF}_{4}$ plus $\mathrm{HBF}_{4}$, we have been able to extend the above chemistry to polycyclic compounds and bisisochromenes using readily available, inexpensive, easily handled $I_{2}$ as the iodine source, and we have generally obtained cleaner and higher yielding reactions. We have also shown that electrophiles, such as ICl, NIS, NBS, $\mathrm{Br}_{2}, p$ $\mathrm{O}_{2} \mathrm{NC}_{6} \mathrm{H}_{4} \mathrm{SCl}$ and $\mathrm{PhSeBr}$, can be used in this chemistry.

\section{Experimental Section}

\section{General}

${ }^{1} \mathrm{H}$ and ${ }^{13} \mathrm{C} \mathrm{NMR}$ spectra were recorded at 300 and $75.5 \mathrm{MHz}$ or 400 and $100 \mathrm{MHz}$ respectively. Thin layer chromatography was performed using commercially prepared 60-mesh silica gel plates, and visualization was effected with short wavelength UV light $(254 \mathrm{~nm})$ or a basic $\mathrm{KMnO}_{4}$ solution $\left[3 \mathrm{~g}\right.$ of $\mathrm{KMnO}_{4}+20 \mathrm{~g}$ of $\mathrm{K}_{2} \mathrm{CO}_{3}+5 \mathrm{~mL}$ of $\mathrm{NaOH}(5 \%)+300 \mathrm{~mL}$ of $\mathrm{H}_{2} \mathrm{O}$ ]. All melting points are uncorrected. Low resolution mass spectra were recorded on a triple quadrupole mass spectrometer. High resolution mass spectra were recorded on a double focusing magnetic sector mass spectrometer using EI at $70 \mathrm{eV}$.

\section{Reagents}

All reagents were used directly as obtained commercially unless otherwise noted.

\section{Supplementary Material}

Refer to Web version on PubMed Central for supplementary material.

\section{Acknowledgements}

We thank the donors of the Petroleum Research Fund, administered by the American Chemical Society, the National Institute of General Medical Sciences (GM070620) and the National Institutes of Health (KU Chemical Methodologies and Library Development Center of Excellence, P50 GM069663) for financial support of this research. We also thank Johnson Matthey, Inc., and Kawaken Fine Chemicals Co., Ltd., for donations of palladium salts. The authors thank Dr. Xiaoxia Zhang for help in the preparation of this manuscript.

\section{References}

1. (a) Lotagawa O, Inoue T, Taguchi T. Rev Heteroatom Chem 1996;15:243. b Frederickson M, Grigg R. Org Prep Proc Int 1997;29:33. c Cardillo G, Orena M. Tetrahedron 1990;46:3321.

2. Drenth, W. Chemistry of Triple-Bonded Functional Groups. Patai, S., editor. 2. J. Wiley; Chichester, UK: 1994. p. 873-915.Schmid, GH. Chemistry of the Carbon-Carbon Triple Bond. Patai, S., editor. 1. J. Wiley; Chichester, UK: 1978. p. 275-341.Larock, RC. Acetylene Chemistry. Diederich, F.; Stang, PJ.; Tykwinski, RR., editors. Wiley-VCH; Weinheim, Germany: 2005. p. 51-99.

3. (a) Arcadi A, Cacchi S, Fabrizi G, Marinelli F, Moro L. Synlett 1999:1432. b Yue D, Yao T, Larock RC. J Org Chem 2005;70:10292. [PubMed: 16323837] c Yao T, Yue D, Larock RC. J Comb Chem 2005;7:809. [PubMed: 16283788]

4. (a) Yue D, Larock RC. J Org Chem 2002;67:1905. [PubMed: 11895409] b Hessian K, Flynn B. Org Lett 2003;5:4377. [PubMed: 14602004] c Flynn BL, Verdier-Pinard P, Hamel E. Org Lett 2001;5:651. [PubMed: 11259028]

5. Huang Q, Hunter JA, Larock RC. J Org Chem 2002;67:3437. [PubMed: 12003556]

6. (a) Yue D, Larock RC. Org Lett 2004;6:1037. [PubMed: 15012094] b Barluenga J, Trincado M, Rubio E, González JM. Angew Chem, Int Ed 2003;42:2406. c Amjad M, Knight DW. Tetrahedron Lett 2004;45:539. 
7. (a) Yao T, Larock RC. J Org Chem 2003;68:5936. [PubMed: 12868929] b Bellina F, Biagetti M, Carpita A, Rossi R. Tetrahedron 2001;57:2857. c Bellina F, Biagetti M, Carpita A, Rossi R. Tetrahedron Lett 2001;42:2859.

8. Yao T, Larock RC. J Org Chem 2005;70:1432. [PubMed: 15704980]

9. (a) Yao T, Campo MA, Larock RC. Org Lett 2004;6:2677. [PubMed: 15281742] b Yao T, Campo MA, Larock RC. J Org Chem 2005;70:3511. [PubMed: 15844984] c Goldfinger MB, Crawford KB, Swager TM. J Am Chem Soc 1997; 119:4578. d Goldfinger MB, Swager TM. J Am Chem Soc 1994;116:7895.

10. (a) Knight DW, Redfern AL, Gilmore J. J Chem Soc, Perkin Trans 1 2002:622. b Arcadi A, Cacchi S, Giuseppe SD, Fabrizi G, Marinelli F. Org Lett 2002;4:2409. [PubMed: 12098259] c Djuardi E, McNelis E. Tetrahedron Lett 1999;40:7193. f Marshall JA, Yanik MM. J Org Chem 1999;64:3798. d Arcadi A, Cacchi S, Fabrizi G, Marinelli F, Moro L. Synlett 1999:1432. e Knight DW, Redfern AL, Gilmore J. J Chem Soc, Chem Commun 1998:2207. f Redfern AL, Gilmore J. Synlett 1998:731. g Ren XF, Konaklieva MI, Shi H, Dicy H, Lim DV, Gonzales J, Turos E. J Org Chem 1998;63:8898. h Bew SP, Knight DW. J Chem Soc, Chem Commun 1996:1007. i El-Taeb GMM, Evans AB, Jones S, Knight DW. Tetrahedron Lett 2001;42:5945. j Zhang X, Campo MA, Yao T, Larock RC. Org Lett 2005;7:763. [PubMed: 15727435] k Zhang X, Larock RC. J Am Chem Soc 2005;127:12230.

[PubMed: 16131194] 1 Yao T, Zhang X, Larock RC. J Org Chem 2005;70:7679. [PubMed: 16149799]

11. (a) Asao N, Nogami T, Takahashi K, Yamamoto Y. J Am Chem Soc 2002;124:764. [PubMed: 11817947] b Nakamura H, Ohtaka M, Yamamoto Y. Tetrahedron Lett 2002;43:7631.

12. Barluenga J, Vazquez-Villa H, Ballesteros A, González JM. J Am Chem Soc 2003;125:9028. [PubMed: 15369355]

13. For a recent review on multicomponent reactions, see: Dömling A, Ugi I. Angew Chem, Int Ed 2000;39:3168.

14. For a previous communication, see: Yue D, Della Cá N, Larock RC. Org Lett 2004;6:1581. [PubMed: 15128241]

15. Tovar JD, Swager TM. J Org Chem 1999;64:6499.

16. Sonogashira, K. Metal-Catalyzed Cross-Coupling Reactions. Diederich, F.; Stang, PJ., editors. Chpt 5. Wiley-VCH; Weinheim: 1998. p. 203-229. (b) Sonogashira K, Tohda Y, Hagihara N. Tetrahedron Lett 1975:4467.

17. For metal-catalyzed synthesis of naphthalenes, see: (a) Asao N, Takahashi K, Lee S, Kasahara T, Yamamoto Y. J Am Chem Soc 2002;124:12650. [PubMed: 12392398] b Asao N, Nogami T, Lee S, Yamamoto Y. J Am Chem Soc 2003;125:10921. [PubMed: 12952473] c Asao N, Kasahara T, Yamamoto Y. Angew Chem, Int Ed 2003;42:3504.For the iodonium ion-prompted synthesis of napthalenes, see: (d) Barluenga J, Vazquez-Villa H, Ballesteros A, González JM. Org Lett 2003;5:4121. [PubMed: 14572264] e Barluenga J, Vázquez-Villa H, Ballesteros A, González JM. Adv Synth Catal 2005;347:526.

18. (a) Suzuki A. J Organomet Chem 1999;576:147. b Lloyd-Williams P, Giralt E. Chem Soc Rev 2001;30:145.Suzuki, A. Metal-Catalyzed Cross-Coupling Reactions. Diederich, F.; Stang, PJ., editors. Wiley-VCH; Weinheim: 1998. p. 49-97. (d) Miyaura N. Chem Rev 1995;95:2457.

19. (a) Negishi E, Dumond Y. Handbook of Organopalladium Chemistry for Organic Synthesis 2002;1:767. b Kosugi M, Fugami K. Handbook of Organopalladium Chemistry for Organic Synthesis 2002;1:263. c Kosugi M, Fugami K. J Organomet Chem 2002;653:50.

20. (a) Crisp GT. Chem Soc Rev 1998;27:427.Brase, S.; De Meijere, A. Metal-Catalyzed Cross-Coupling Reactions. Diederich, F.; Stang, PJ., editors. Wiley-VCH; Weinheim: 1998. p. 99-166.Heck, RF. Palladium Reagents in Organic Synthesis. Academic Press; San Diego: 1985. p. 276-287.

21. Larock RC, Doty MJ, Han X. J Org Chem 1999;64:8770. [PubMed: 11674778] 


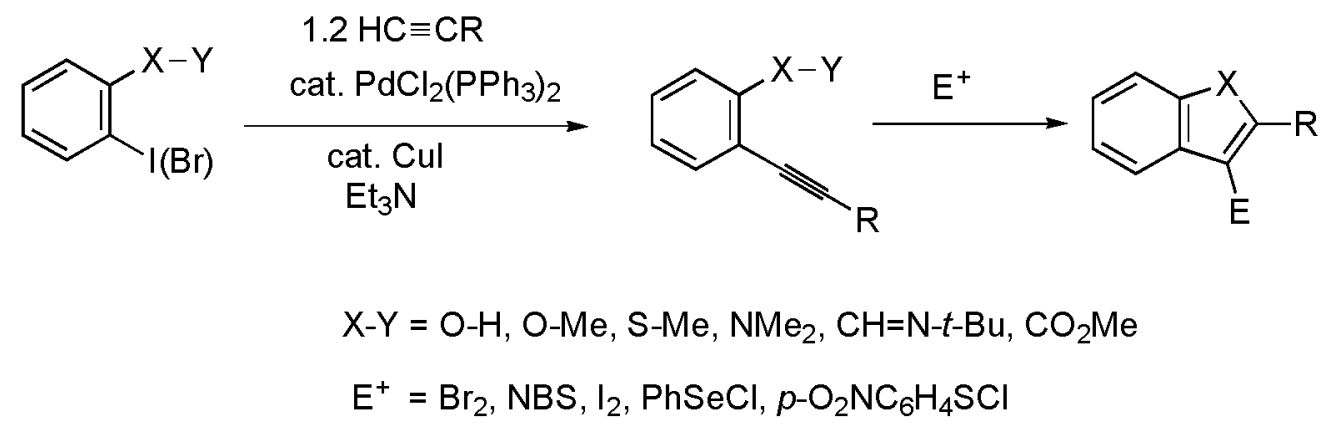

Scheme 1. 
<smiles>[R]C#Cc1ccccc1C=O</smiles>

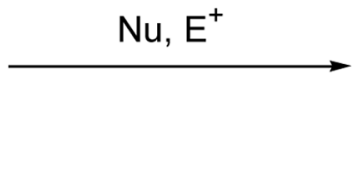<smiles>[R]C1=C(F)c2ccccc2C(N)O1</smiles>

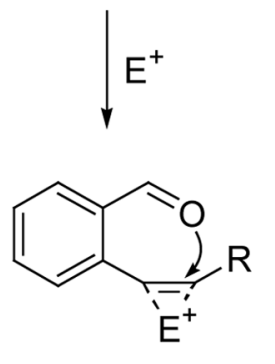
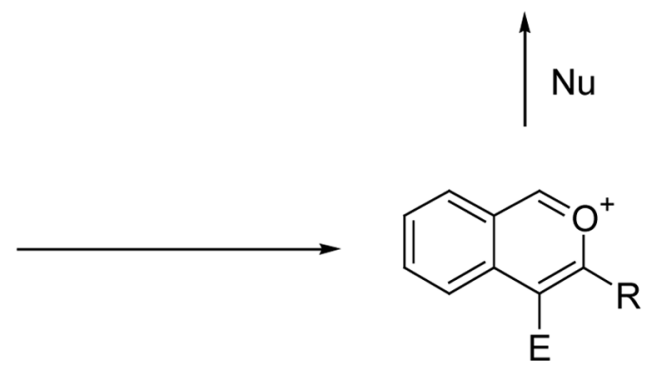

Scheme 2. 
<smiles>C#Cc1ccccc1-c1ccccc1C#Cc1ccccc1C=O</smiles>

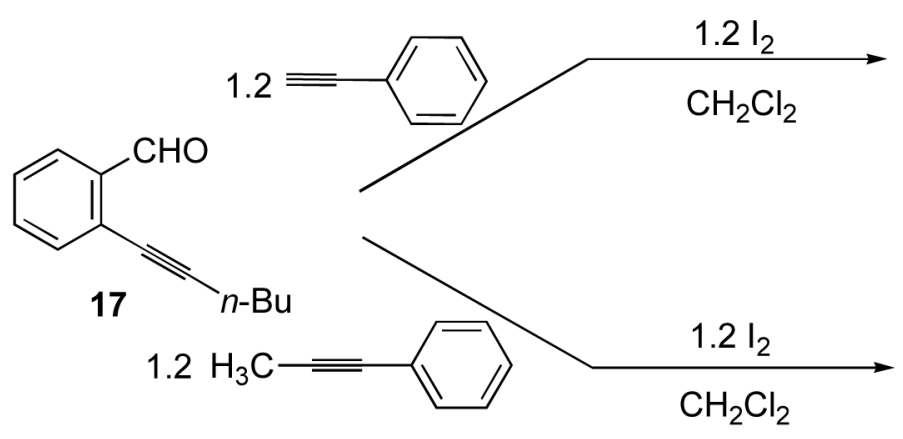<smiles>[13CH3]</smiles>

Scheme 3 . 


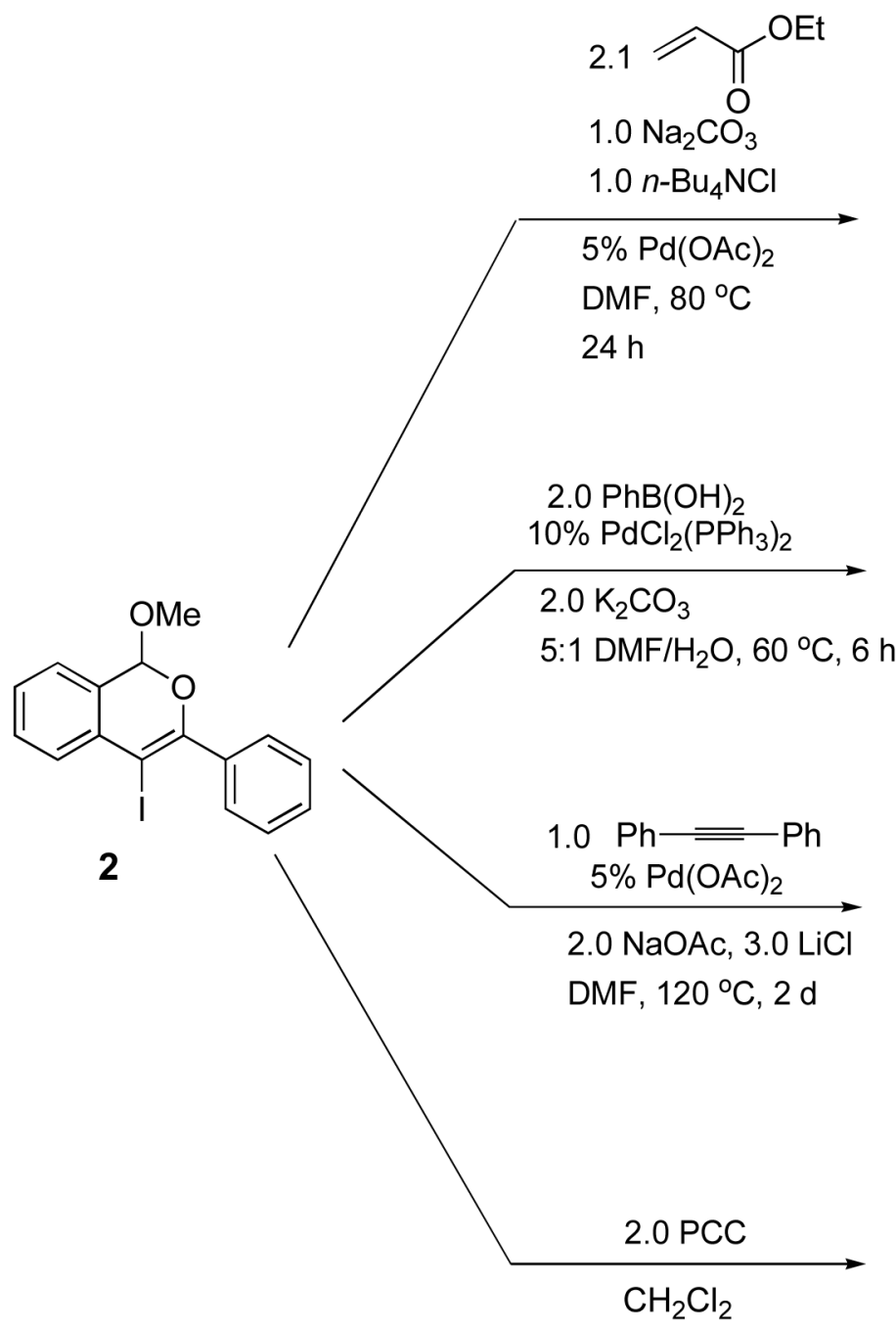<smiles>CCOC(=O)OCC=CC1=C(c2ccccc2)OC(OC)c2ccccc21</smiles><smiles>COC1OC(c2ccccc2)=C(c2ccccc2)c2ccccc21</smiles>

47 (79\%)<smiles></smiles>

49 (81\%)

Scheme 4. 
Table 1

Iodocyclization of 2-(phenylethynyl)benzaldehyde

\begin{tabular}{|c|c|c|c|c|}
\hline solvent & $\stackrel{1}{\operatorname{MeOH}(\text { equiv) }}$ & $\begin{array}{c}\frac{\mathrm{I}_{2}}{\text { base }} \\
\mathbf{I}_{\mathbf{2}} \text { (equiv) }\end{array}$ & base (equiv) & yield $(\%)$ \\
\hline $\mathrm{CH}_{2} \mathrm{Cl}_{2}$ & 1.2 & 1.2 & $\mathrm{~K}_{2} \mathrm{CO}_{3}(1.0)$ & 88 \\
\hline $\mathrm{CH}_{3} \mathrm{CN}$ & 1.2 & 1.2 & $\mathrm{~K}_{2} \mathrm{CO}_{3}(1.0)$ & 40 \\
\hline DMF & 1.2 & 1.2 & $\mathrm{~K}_{2} \mathrm{CO}_{3}(1.0)$ & trace \\
\hline $\mathrm{CH}_{2} \mathrm{Cl}_{2}$ & 1.2 & 1.2 & $\mathrm{KHCO}_{3}(1.0)$ & 70 \\
\hline $\mathrm{CH}_{2} \mathrm{Cl}_{2}$ & 1.2 & 1.2 & $\mathrm{Et}_{3} \mathrm{~N}$ & - \\
\hline $\mathrm{CH}_{2} \mathrm{Cl}_{2}$ & 2.0 & 2.5 & $\mathrm{~K}_{2} \mathrm{CO}_{3}(1.0)$ & 80 \\
\hline $\mathrm{CH}_{2} \mathrm{Cl}_{2}$ & 2.0 & 2.5 & $\mathrm{~K}_{2} \mathrm{CO}_{3}(2.0)$ & 78 \\
\hline $\mathrm{MeOH}$ & - & 2.5 & $\mathrm{~K}_{2} \mathrm{CO}_{3}(2.0)$ & 68 \\
\hline
\end{tabular}




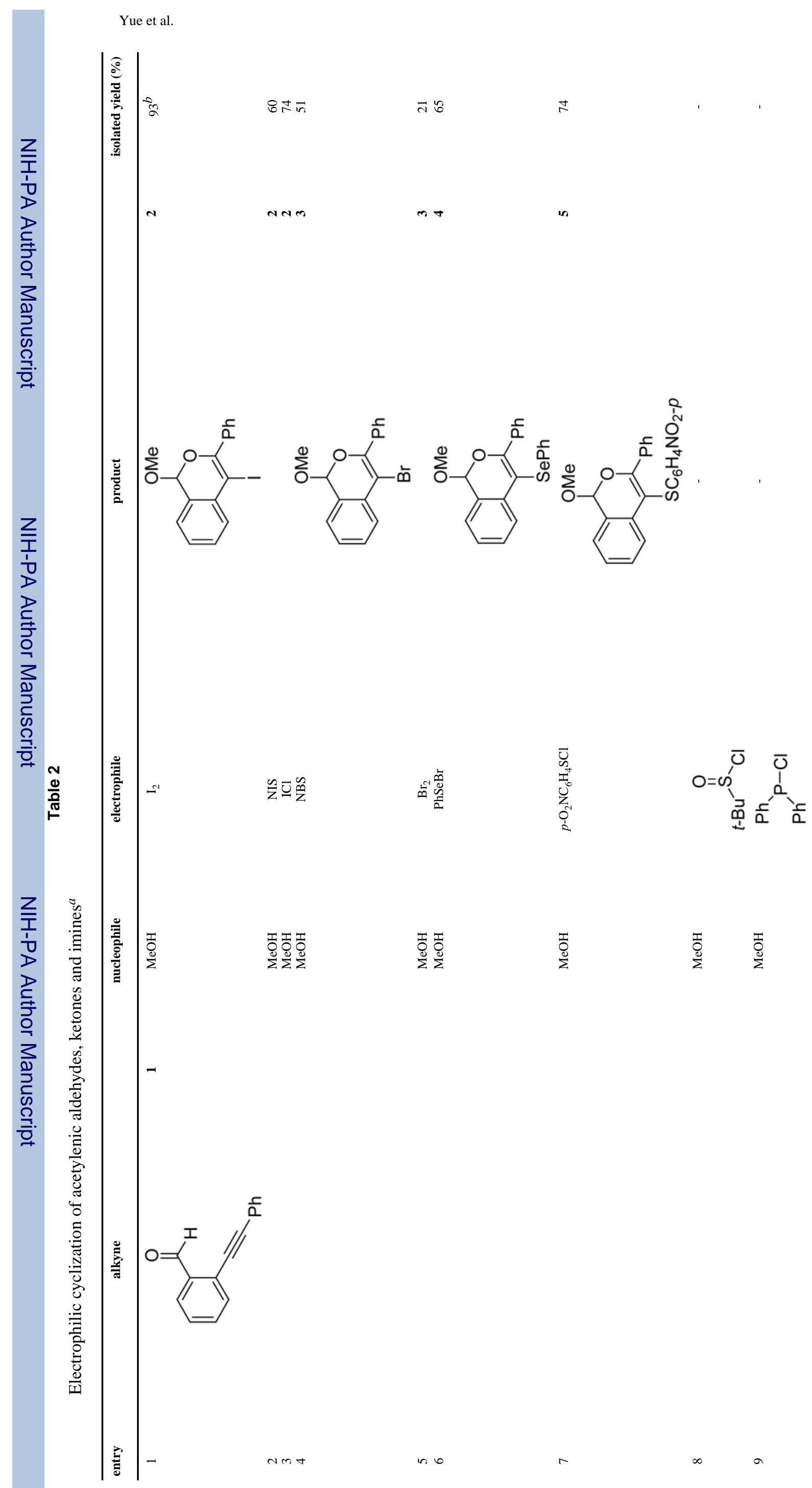

Page 12 


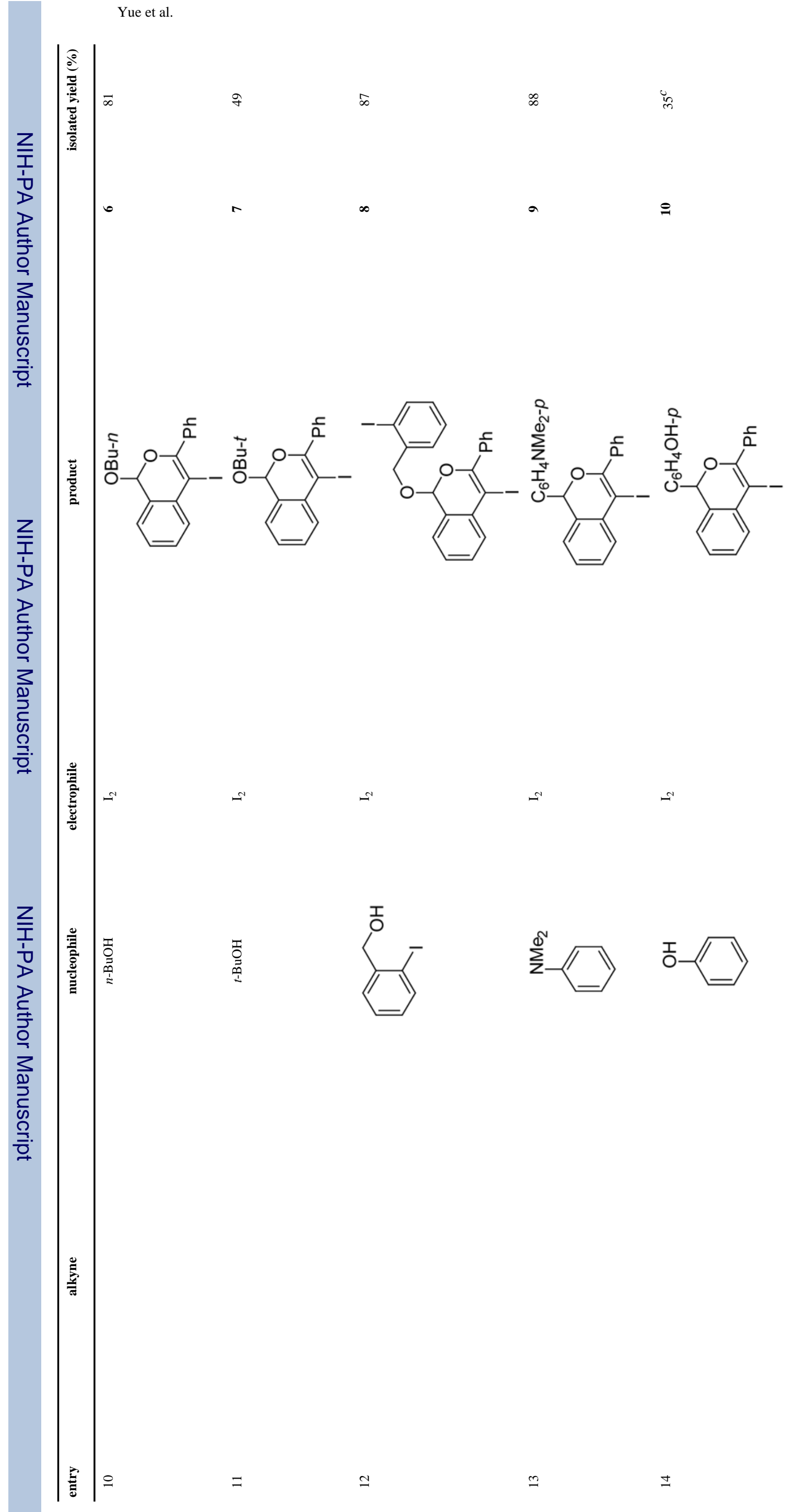




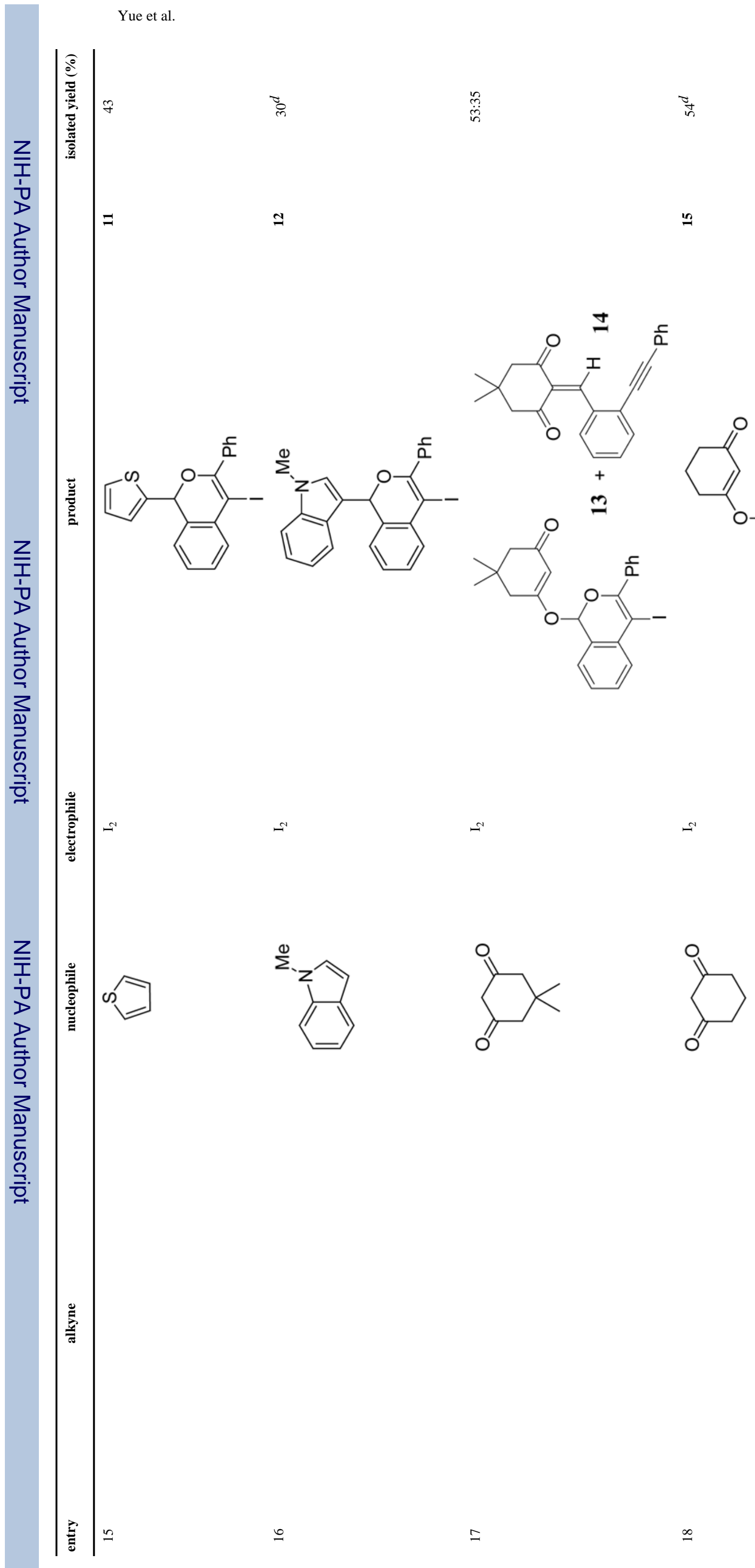

Page 14 


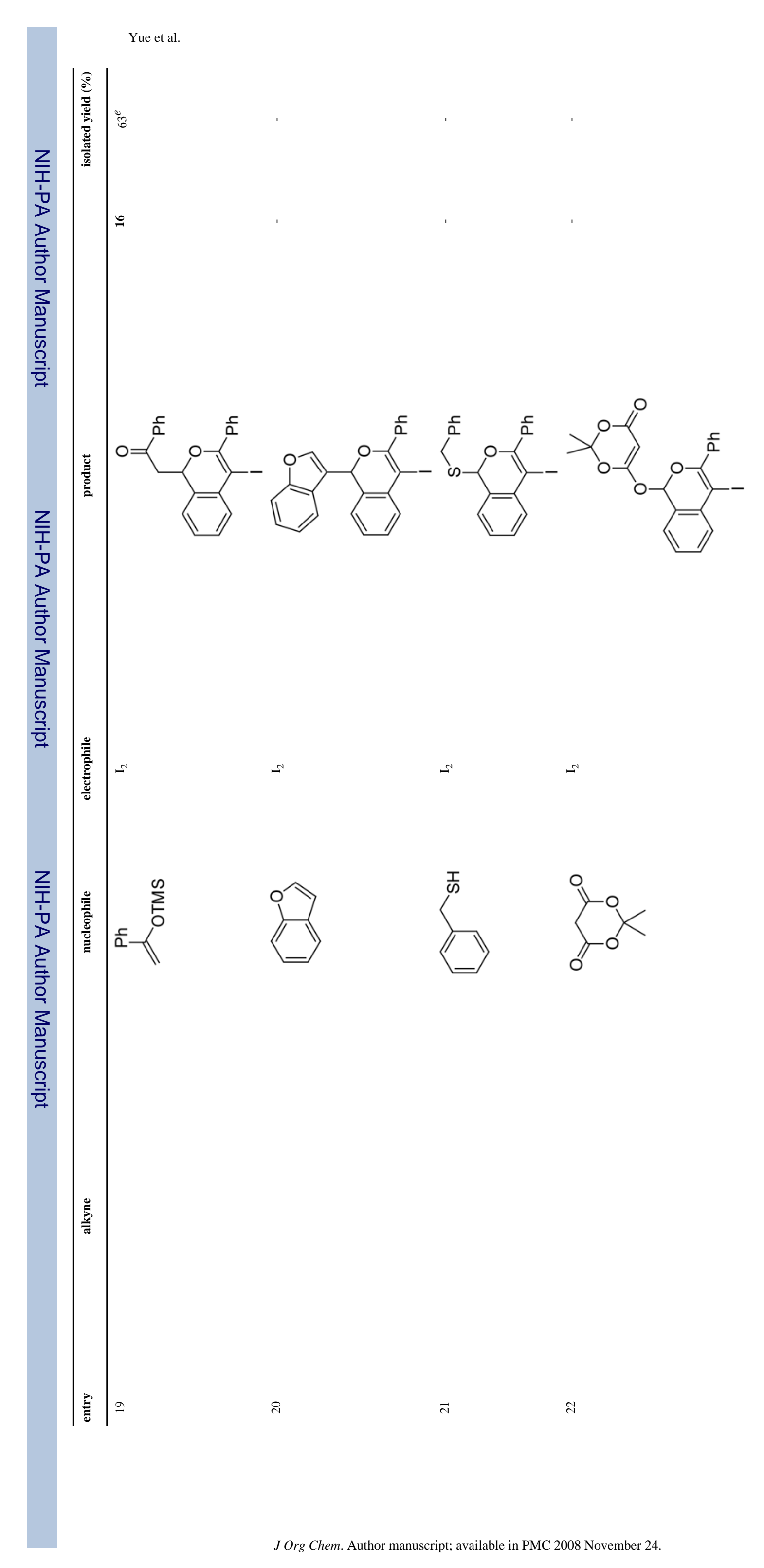




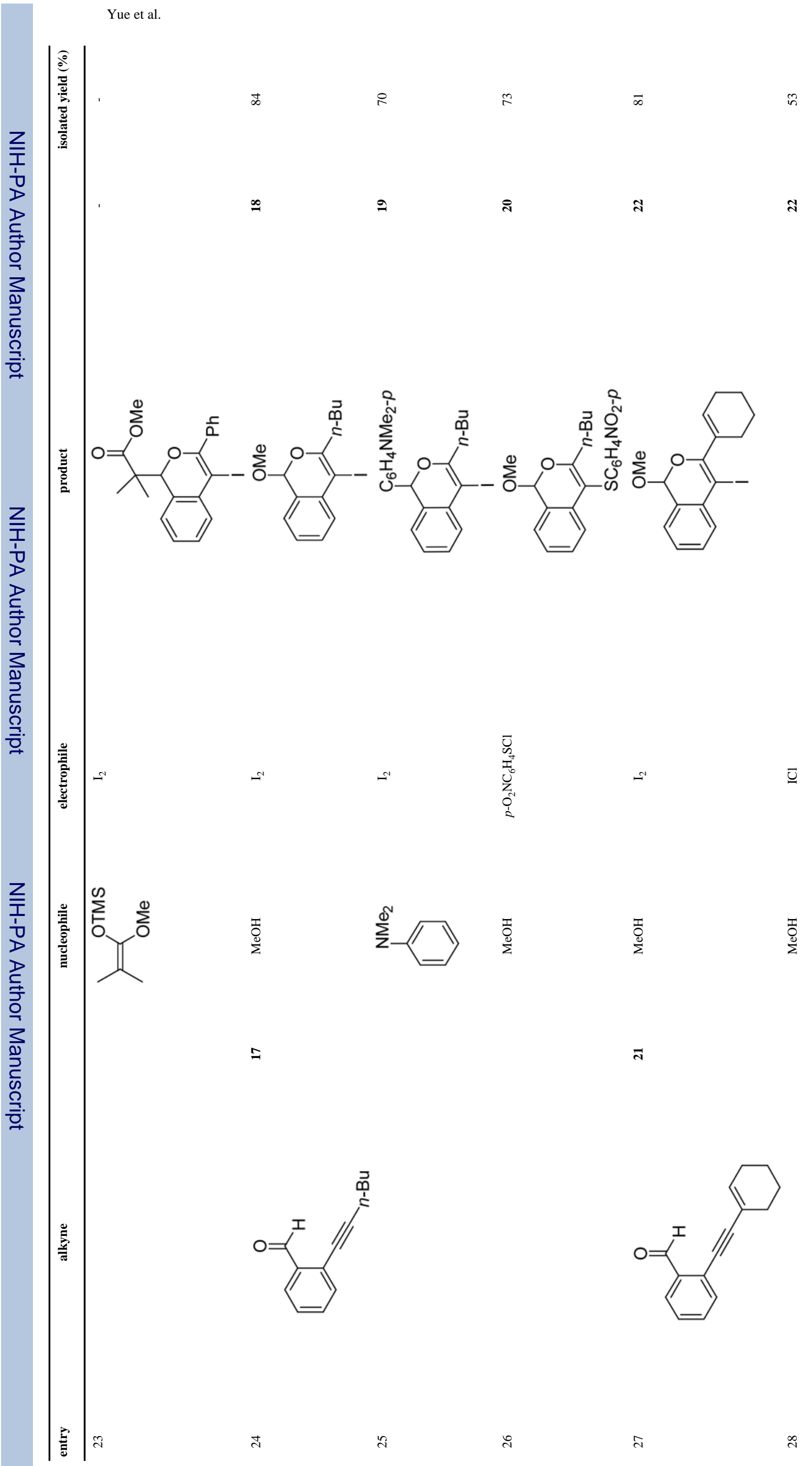

Page 16

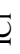




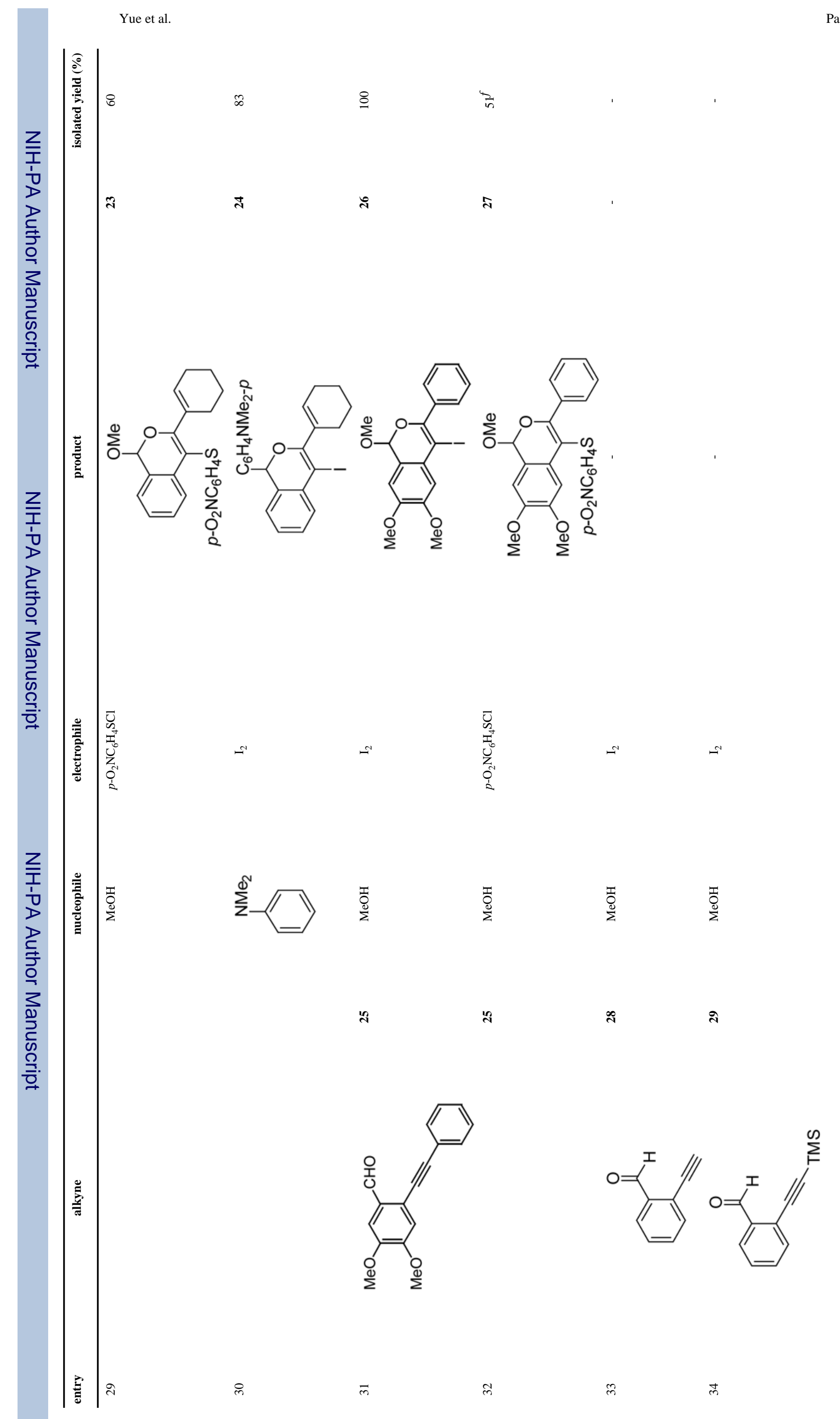




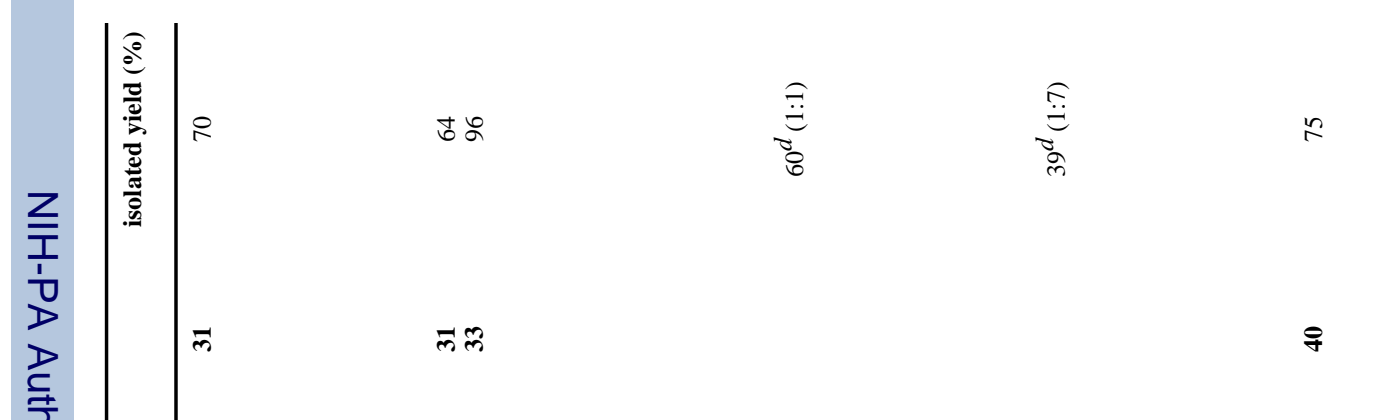

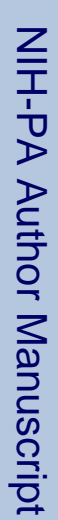

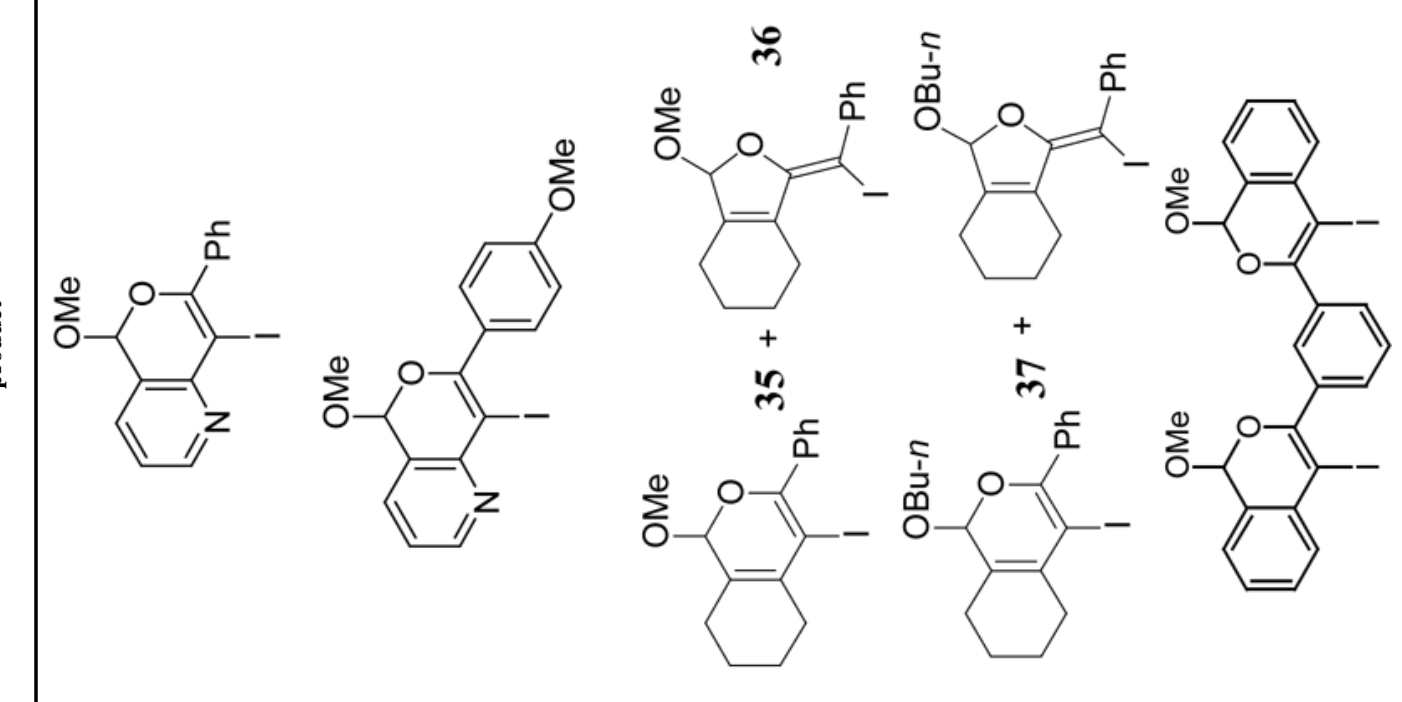

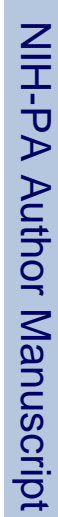

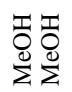

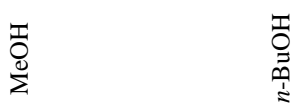

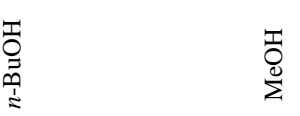

$\approx$

ฮ઼

$\frac{n}{z}$

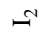

$\hat{m}$
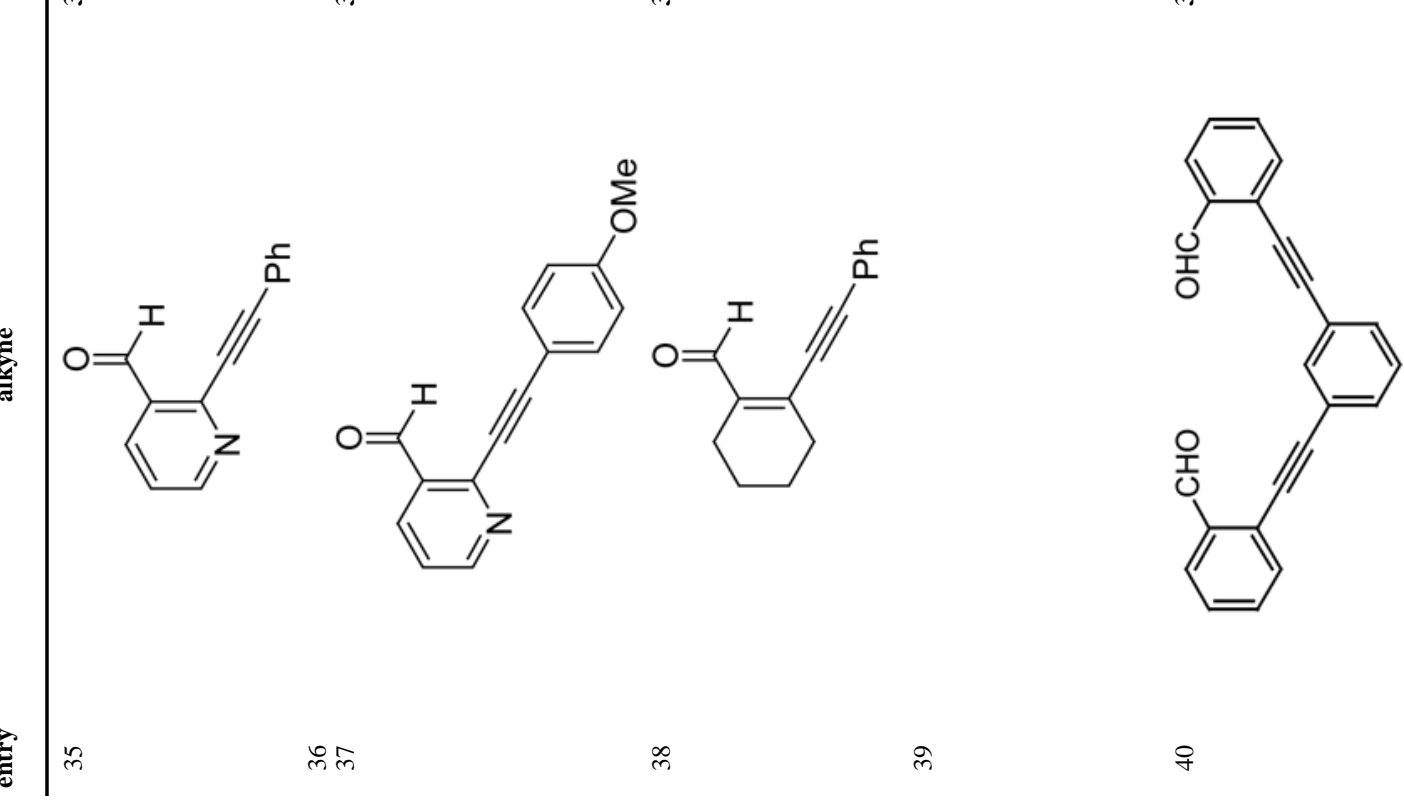

กn

$\infty$

\& 


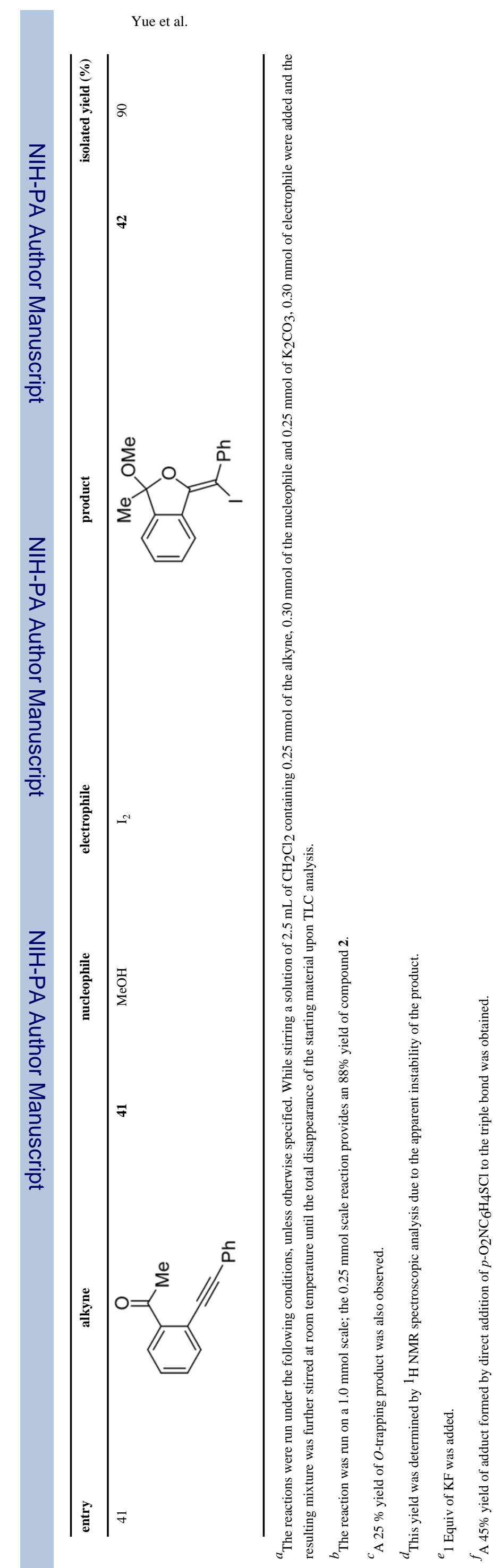

Page 19 